\title{
pedro bloch : um escutador da graça das crianças
}

\author{
camila rodrigues ${ }^{1}$ \\ universidade de são paulo - brasil
}

resumo

Na segunda metade do século XX, o médico foniatra, jornalista e escritor Pedro Bloch (1914 -2004), manteve uma seção humorística contando historinhas de criança nas revistas Manchete e Pais $\mathcal{E}$ Filhos, que depois transformou em livros, os seus anedotários infantis. Além de ele próprio conversar com seus pequenos pacientes no consultório e recolher matéria prima para escrever seus textos, Bloch também incentivava seus leitores e conhecidos adultos a ouvirem a meninada, pois assim eles experimentariam o contato revelador com aquela peculiar percepção do mundo, que é o que ele procurava expor em suas anedotas. $\mathrm{O}$ intuito de escutar os pequenos e dialogar com eles era a chave do trabalho bloquiano com a meninada, o que chamamos Projeto Criança diz cada uma!, mas também correspondia a uma tendência na época,seguida por intelectuais como João Guimarães Rosa e Walter Benjamin, que não apenas passaram a ouvir a meninada, como também a registrar suas elocuções, sempre na intenção de inseri-las no diálogo histórico cultural. Neste texto procuramos sublinhar o trabalho bloquiano com o humor e a oralidade das crianças, e também discutir suas consequências para a escrita de uma nova História da infância, que considere também a voz dos pequenos sobre si mesmos.

palavras-chave: criança; humor; pedro bloch.

\section{pedro bloch: a listener of the children's grace}

abstract

In the second half of the twentieth century, the medical doctor, journalist and writer Pedro Bloch (1914-2004), maintained a humorous section telling children stories in the magazines Manchete and Pais \& Filhos, which later turned into books: his children's anecdotes. In addition to himself talking to his little patients in the office and collecting raw material to write his texts, Bloch also encouraged his readers and well-known adults to listen to the boys, so that they could experience the revealing contact as that peculiar perception of the world, which is the precisely what he sought to express in his anecdotes. The intention to listen to the children and to dialogue with them was the key to the work of the Bloch with the children, what we call Project "Criança diz cada uma!", but also corresponded to a trend at the time, followed by intellectuals like João Guimarães Rosa and Walter Benjamin, who went not only to listen to the children, but also to record their utterances, always with the intention of inserting them in the historical cultural dialogue. In this text we try to present the work of Bloch with the humor and the orality of the children, and also to discuss its consequences for the writing of a new History of the childhood, that also considers the voice of the small ones about themselves.

keywords: child; humor; pedro bloch.

\footnotetext{
${ }^{1}$ E-mail: onapomona@gmail.com 
pedro bloch: um escutador da graça das crianças

\section{pedro bloch: un escuchador de la gracia de los niños}

resumen

En la segunda mitad del siglo XX, el médico foniatra, periodista y escritor Pedro Bloch (1914 -2004), mantuvo una sección humorística contando historias de niños en las revistas Manchete y Pais $\mathcal{E}$ Filhos, que luego transformó en libros, sus anecdotarios infantiles. Además de conversar él mismo con sus pequeños pacientes en el consultorio y recoger materia prima para escribir sus textos, Bloch también alentaba a sus lectores y conocidos adultos a escuchar a los niños, pues así ellos experimentarían el contacto revelador con aquella peculiar percepción del mundo, que es lo que él buscaba exponer en sus anécdotas. La intención de escuchar a los pequeños y dialogar con ellos era la clave del trabajo blochiano con la infancia, lo que llamamos Projeto Criança diz cada uma! Esta actitud correspondía a una tendencia de la época, seguida por intelectuales como João Guimarães Rosa y Walter Benjamin, que pasaron no sólo a oír a los niños sino también a registrar sus elocuciones, siempre con la intención de insertarlas en el diálogo histórico cultural. En este texto buscamos presentar el trabajo blochiano con el humor y la oralidad de los niños y también discutir sus consecuencias para la escritura de una nueva historia de la infancia, que considere también la voz de los pequeños sobre sí mismos.

palabras clave: niño; humor; pedro bloch. 
pedro bloch : um escutador da graça das crianças

\section{introdução: pedro bloch e o humor com crianças}

No Rio de Janeiro da segunda metade do século XX, Pedro Bloch foi um jornalista, dramaturgo e médico da fala que também era especializado em tratar crianças com dificuldade de comunicação oral e que, a partir da década de 1950, manteve uma coluna humorística na revista Manchete com as anedotas inspiradas nas peculiares falas da meninada que ouvia em consultório, chamada "Criança diz cada uma!", que décadas depois também começou a ser veiculada em outra publicação de propriedade de sua família, a revista Pais e Filhos .

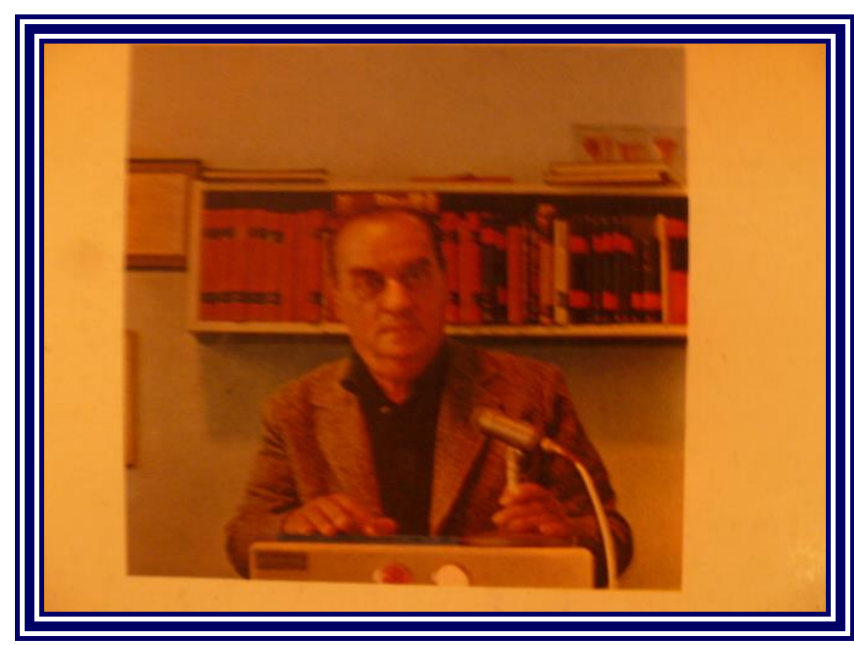

Figura 1 - Foto de Pedro Bloch no livro Outras de criança diz cada uma Fonte: (BLOCH,1983)

Depois de ouvir as facécias infantis, Pedro Bloch as escreve, transformadoas em anedotas, que é um gênero narrativo humorístico que diz respeito à narração curta de um fato jocoso ou curioso. Anedota também é sinônimo de piada e esta, além de significar algo engraçado, é também o particípio passado do verbo piar - que é o falar dos passarinhos -, estes animais que, juntamente com os anjos, simbolizam a intermediação entre a terra e o céu (CHEVALIER; GHEERBRANT, p. 690), mantendo profunda relação com o universo da graça e cuja intervenção é facilmente percebida pela garotada, justificando assim o interesse por ela quando se pensa em humor e crianças, como acontecia com nosso autor. 
Por diversas vezes Pedro Bloch chegou a declarar o quanto gostava de ser reconhecido como "o homem que conta historinhas de criança" (BLOCH, 1974, p.118-9), coisas que ele coletava, colecionava e escrevia, porque reconhecia esboçados nelas, traços de uma espécie de sabedoria infantil (HUIZINGA, 2001, p. 133-4), percepção que, na época, ainda era pouco absorvida, conforme antevemos na própria argumentação de Bloch:

O mundo infantil é cheio de mistério e poesia, suspense e humor. [...] Seria
de desejar que todos os pais guardassem as frases mais expressivas dos
filhos, como verdadeiros tesouros. Mas o que ocorre, normalmente, é que
se conserva um flagrante fotográfico inexpressivo ou uma botinha, um
boneco uma mecha de cabelo. Quase nunca percebe que o que a criança
diz, em suas diferentes fases, são pedacinhos de alma dessa criança.
(BLOCH, 1963, p. 1. Grifo nosso)

No inovador trabalho literário bloquiano, centrado na oralidade dos pequenos que depois inspiraram textos para a coluna Criança diz cada uma!, cabe observar que o primeiro objetivo do autor era o de expor, na imprensa, o universo da meninada ao adulto de forma leve e engaçada, mas logo ele também ganhou leitores entre a garotada. Inicialmente supomos que isso tenha acontecido naturalmente porque naqueles textos cômicos, o papel destinado às crianças se expande e elas atuam não apenas como personagens, mas também como coautoras e leitoras de narrativas engraçadas, o que é algo excepcional para a época, sublinhando uma das peculiaridades daquele plano junto à meninada.

\section{projeto criança diz cada uma!}

Denominamos Projeto criança diz cada uma! o conjunto de atuações de Pedro Bloch com as crianças e isso consistia em, de início, coletar ele próprio em seu consultório, onde conversava com os pequenos, algumas divertidas historinhas infantis para preencher sua coluna em revistas e livros de anedotas. Além disso, como bom interlocutor da meninada, nosso doutor aventou que muitos dos problemas de seus pacientes mirins apareciam sempre que os pais e adultos não os inseriam no diálogo, o que poderia facilitar a comunicação entre adultos e crianças.

Nas palavras do próprio Bloch, seu intento com os infantes consistia em 
reunir, retrabalhar sua comicidade e divulgar as "definições", "observações" e "criações de todo o gênero" retiradas de conversas com crianças e também de "contribuições de pais, amigos, leitores e pessoas que sabem ouvir a criança" (BLOCH, 1998, p.10). Olhando para esse material sublinhamos de que forma o autor usou o humor para possibilitar que a voz da criança fosse, enfim, ouvida.

Para ampliar a circulação do projeto, Bloch também defendeu a prática da conversação com os pequenos entre seus conhecidos - que em geral eram pessoas afamadas às quais foi apresentado devido aos seus trabalhos no teatro e jornalismo -, o que permitiu que ele convivesse e aglutinasse em suas relações interpessoais escritores, atores, cantores, artistas em geral, tendo militado com todos para que anotassem e lhe trouxessem as falas e histórias infantis ouvidas de crianças que escutassem, o que pode ter pontuado a mudança na própria forma de conceber a criança como um indivíduo no meio social que estava em processo na época.

Conforme veremos mais detalhadamente neste texto, Bloch usou a comicidade como filtro facilitador na comunicação entre adultos e crianças e para conseguir isso ele precisou refletir muito sobre o tema em considerações como esta:

[...] o humor infantil, o que a criança diz, tem características tão próprias, tão originais, tão suas, que os referenciais do adulto não conseguem fixar com facilidade. [...] É que aqueles seres pequeninos parecem ter uma infinidade de segredinhos, de particulares, de confidências e mistérios. Se compreendem mais pelo implícito do que pelo proferido. E o proferido é, quase sempre, o preferido. (BLOCH, 1980. p. 111-2)

Ao escolher o trabalho de Pedro Bloch com as crianças como objeto de análise em nossa pesquisa, apostamos que ele possa abrir uma boa chance de abordarmos uma área recente da historiografia chamada História Cultural do Humor (BREMMER; ROODENBURG, 2000), que aposta na comicidade como chave para a compreensão de fenômenos históricos e culturais e procura registros de práticas humorísticas. Como esta área da História voltada à comicidade ainda é muito recente, por hora não contamos com reflexões epistemológicas de peso sobre ela. Mesmo sobre o próprio humor não temos nenhuma acepção definitiva, embora tenhamos algumas teorias mais citadas (Cf., entre outros, BERGSON,2007; 
FREUD, 1953; PIRANDELLO, 1999), que como toda a bibliografia, devem servir ao historiador cultural como amparo crítico na interpretação das fontes. Por outro lado, já sabemos que muitas pesquisas empíricas sobre Humor estão sendo desenvolvidas mundialmente, e em 2014 um levantamento delas já foi até publicado em uma Enciclopédia de Estudos sobre Humor ${ }^{2}$, na qual um dos maiores verbetes é justamente o que aborda o humor de crianças (ATTARDO, 2014, p. 120-27).

Segundo a História Cultural, o historiador deve partir das fontes e a partir delas procurar "reconstruir os espaços de ruptura, os registros de alguns silêncios e as manifestações pontuais e fragmentadas" (SALIBA, 2002), para tentar se aproximar de pontos do passado de difícil acesso, como a percepção e a sensibilidade das épocas. Por isso nossas pesquisas podem parecer muito fragmentadas, mas faz parte de uma prática analítica usada pelos pesquisadores da História do humor apostar em uma abordagem que prime por uma subjetividade epistemológica, dialogando com várias perspectivas, mas sempre se ancorando em uma objetividade metodológica na leitura das fontes.Em relação ao programa bloquiano, destacamos que sua prática centrava-se no uso da comicidade infantil e na exploração da oralidade em território clínico e também podemos afirmar que, como autor, ele foi um humorista, afinal ele produziu objetos cômicos que podem servir de fonte de pesquisa a estudos, a saber, as anedotas escritas a partir das falas da meninada e publicadas em sua coluna humorística nas revistas; os dicionários de humor infantil (BLOCH, 1998a e 2001) e as antologias de anedotas infantis (anedotários), sobre as quais aqui vamos tratar.

\section{anedotários infantis}

Dentre as inúmeras publicações bloquianas relacionadas a crianças, para abordar seu trabalho com a meninada e o humor, nossa investigação bibliográfica apontou para uma seleção de onze volumes de historinhas engraçadas confeccionadas a partir da fala infantil que foram publicados entre 1963 e 1998,

\footnotetext{
2 Tradução nossa para "Encyclopedia of humor studies".
} 
nos quais são problematizadas as funções, a frequência e a utilidade da comicidade na vida humana desde a sua mais tenra idade, a saber : Criança diz cada uma! (1963)3; Essas crianças de hoje (1970); O menino falou e disse (1974); Poxa, que meninos! (1977); Criança é isso ai (1980); Esses meninos de ouro! (1983); Outras de 'Criança diz cada uma!' (1983 a); Criança sabe das coisas (1984); Essas crianças fabulosas (1987); O incrível humor da criança (1989) e A sabedoria da criança (1998).
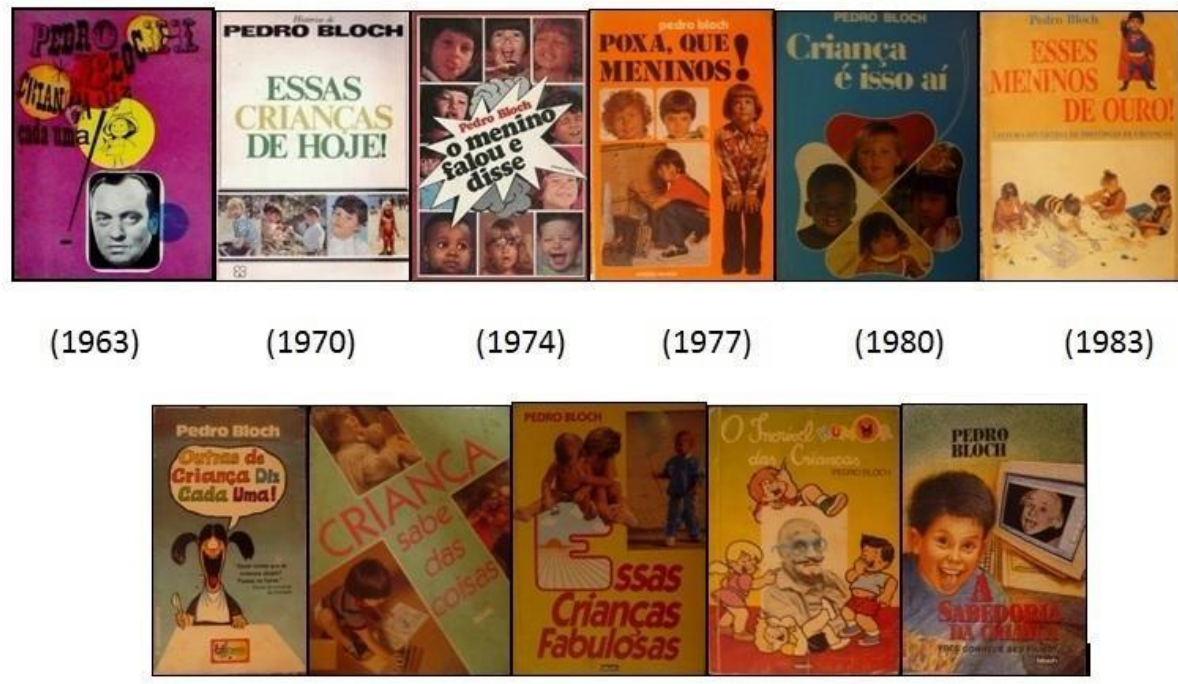

(1983a)

(1984)

(1987)

(1989)

(1998)

Figura 2 - Capas dos anedotários de Pedro Bloch

Em geral estes são livros pequenos e de leitura ágil e divertida e observando suas capas, vemos representações de crianças e do próprio Pedro Bloch, em fotos ou desenhos, indicando que ali estamos diante do resultado de um trabalho com humor envolvendo a participação direta da meninada em conjunto com seu escutador adulto Pedro Bloch. Já na primeira das publicações selecionadas, nosso autor faz um comentário explicativo que pode ser estendido aos outros dez volumes, quando se assume como escutador de crianças ao explicar que ali: "reuni uma série de coisas ditas e observadas no mundo das crianças. Foi das experiências mais fascinantes de minha vida" (BLOCH, 1963, p.1).

Para a escrita de Bloch era fundamental permitir que a criança pudesse

3 Criança diz cada uma! é o título que sintetiza a ideia do projeto de Pedro Bloch em reunir historinhas de crianças, reescrevê-las e publicar na imprensa e em livros. Também com esse nome sabemos que existem muitos volumes, algumas revistinhas, mas aqui nos referimos a este de 1963, que seria o primeiro anedotário infantil bloquiano ao qual tivemos acesso. 
pedro bloch: um escutador da graça das crianças

expressar livremente seus posicionamentos para que ele registrasse, pois ali encontraríamos portas de entrada para o mundo mágico e divertido da garotada e também conheceríamos melhor a sua sabedoria. Refletindo sobre como o humor poderia atuar como facilitador na comunicação entre adultos e crianças Bloch comenta :

Muita gente grande faz concessões à sabedoria da criança. Mas faz, apenas, concessões. Acham mais graça no tatibitate e nos erros que ela comete do que no que ela possa apresentar de mais profundo, de mais consistente, de mais original. É o resgate de um respeito pela criança, cada vez maior, que este livro pretende, da maneira mais singela. (BLOCH, 1998, p. 9-10)

Dentre outras coisas, assumir esse posicionamento de considerar a voz infantil permitiu ao autor Bloch inaugurar em seus textos uma nova modalidade de relação entre a criança e a comicidade, pois se, tradicionalmente, se pensa em humor infantil como uma narrativa onde a criança é sempre a personagem de quem se ri, nas anedotas bloquianas flagramos o surgimento de uma nova forma, a partir da qual percebemos um destaque para o papel creditado à meninada, que ali atua em diversificados papéis: além de coatoras das narrativas, elas também aparecem como personagens questionadoras e até mesmo como leitoras críticas dos volume bloquianos.

Como exemplos de como Bloch oferecia a oportunidade das crianças atuarem em seus anedotários, escolhemos algumas anedotinhas publicadas nos anedotário nas quais os pequenos aparecem como comentadores de seu projeto em posicionamentos distintos.

Na primeira critica de nossa seleção encontramos uma narrativa que aborda o território da comicidade a partir do ponto de vista de uma criança:

\section{O Homem das historinhas}

O menino queria conhecer, por força, o Pedro Bloch, o homem que o divertia com historinhas de criança que lia. Ao sair do meu consultório, partilhou sua decepção com a mãe:

-Ele é sério. E está vestido de doutor! Eu pensei que ele usasse roupa de palhaço que nem o Carequinha. (BLOCH, 1974, p. 156)

Nesta narrativa ressaltamos que Bloch aparece para o menino como um sujeito produtor de humor, que o pequeno queria encontrar e conhecer pessoalmente. Se as crianças leitoras, personagens e coautoras das anedotas de 
Pedro Bloch dentre as décadas de 1960 e 1990 o reconheciam como humorista cabe destacar que, para aquela meninada, que era exposta a diversos tipos de narrativa, inclusive aos veículos de comunicação de massa (Cf. BENJAMIN, 2015), a tarefa de fazer rir, era comumente executada pelo palhaço (Cf., entre outros, BOLOGNESI, 2003 e DUARTE, 1995), e não era raro que nosso doutor fosse comparado ao comediante Carequinhat, que era reconhecido da televisão. Em uma perspectiva histórica, a figura dos cômicos na cultura brasileira do século XX aponta que “a máscara que o palhaço usa para fazer rir que se confunde de tal forma com ele próprio que ainda que retirada do rosto o público acaba por não reconhecer a pessoa real." (SALIBA,2002, P.132)

Mas as crianças iam percebendo, por elas mesmas, as distinções entre a produção bloquiana e a de um outro tipo de cômico profissional como o palhaço, conforme lemos nesta anedota:

\section{A OPINIÃO DO MENINO}

O maior elogio que recebi de uma criança foi o daquele menino que me entrou pelo consultório a dentro para tratar de um problema de fala. É lógico que, lidando com um pingo de gente, procuro me adaptar à sua mentalidade, à sua maneira de compreender as coisas. Motivação surge pra dar e vender. Muita gente comete o erro de tratar uma criança como se fosse um adulto em miniatura. Uso mil e um brinquedos e mil e uma histórias, mil e um engodos para a emoção e a sensibilidade infantis. Ao sair do consultório a mãe lhe pergunta:

-Então, meu filho, o que foi que você achou do doutor? E o menino, definitivo:

-O homem, mamãe, é tão bom, mas tão bom e tão inteligente... que até parece uma criança. (BLOCH, 1983a, p.100)

Porém, as opiniões da criançada sobre o trabalho bloquiano não eram apenas afirmativas e nos anedotários também encontramos algumas críticas ao seu processo escritural:

\footnotetext{
ANINHA

Aninha tem só três anos repletos de alegria e vivacidade. Alguém quis provocá-la no sentido de dizer uma coisa engraçadinha que saísse publicada neste livro. Ela protestou:

-Por que você não procura outra menina? Quando eu digo uma coisa engraçada ninguém toma nota. Aí a gente esquece. [...] (BLOCH, 1974, p. 121)
}

\footnotetext{
${ }^{4}$ O cômico carioca George Savalla Gomes, o Carequinha (1915-2006) foi um palhaço de televisão desde pelo menos a década de 1950, tendo atuado em emissoras regionais, na TV Tupi, na TV Globo, na TV Manchete e etc, era bastante conhecido das crianças durante todo o período que Pedro Bloch escreveu suas anedotas infantis.
} 
O próprio Pedro Bloch, idealizador desse resgate dos dizeres infantis em suas narrativas cômicas, pensou sobre o motivo pelo qual os adultos rapidamente se esqueciam das tiradas que as crianças soltam, ainda que as tenham considerado geniais quando as ouviram, então propõe uma reflexão intuitiva a respeito do teor cômico daquelas anedotas, pois arrisca supor que devido a enorme originalidade do pensamento infantil, o adulto nem sempre consegue acompanhar. (BLOCH, 1980, p.11-2)

Se os adultos são surpreendidos ao se postarem a ouvir o que a criança diz, também para os pequenos as observações de adultos são instigantes, mesmo que seja um alguém que soubesse ouvir crianças, como é o caso de Bloch:

\section{PEDRINHO}

Pedrinho Tornaghi, um pirralho, ao ouvir as histórias do meu livro 'Criança diz cada uma!', protestou:

- Mas isso não é criança- prodígio! Eu digo essas coisas tôda (sic) ${ }^{5}$ hora! (BLOCH, 1963,p. 210. Grifo do autor).

Se as crianças se reconhecem nas anedotas bloquianas é porque elas devem expressar de forma clara e direta a sua percepção da vida e do mundo, enquanto que, para os adultos, elas não passavam de simples facécias infantis. O choque entre essas duas apreensões contraditórias, muitas vezes, pode resultar em um riso ou um sorriso, o que acaba aproximando de alguma forma tais percepções tão distintas. Quando Bloch escreve anedotas a partir do que ouviu de crianças e convoca-as para colaborar na produção de seus textos cômicos ele também está pontuando uma então nascente sensibilidade em relação aos pequenos, segundo a qual a meninada passou a ser vista não apenas como detentora de uma cultura própria, mas também como produtora de objetos e significados culturais. (COHN,2009, p.33).

Com esta pequena coleção de anedotas esperamos ter esboçados traços da importância da produção humorística bloquiana com as crianças, destacando que ela não apenas respeita, mas privilegia a participação dos pequenos, sendo assim uma espécie de "humor produzido por crianças" (POSSENTI, 1998, p.142), o qual

\footnotetext{
5 Objetivando preservar as marcas do tempo em que os livros foram escritos e publicados incluindo as formas gramaticais utilizadas a cada época -, doravante manteremos a grafia original do texto nas citações, indicando as diferenças em relação às normas vigentes com a sigla (sic).
} 
chamamos de "humor com criança", que seria uma modalidade na qual as assimilações cômicas de adultos e crianças não se diluem completamente, mas preservam um diálogo constante, no qual os pequenos recebem o repertório ofertado pelos grandes, mas the atribui sempre diferenciados significados. (Cf. COHN, 2009, p. 33)

\section{ouvindo crianças}

Lembrando que aquilo que chamamos projeto Criança diz cada uma! não implicava apenas no ouvir crianças por Pedro Bloch, mas ele também incluía incentivar os adultos leitores das colunas nas revistas semanais a dialogarem com as crianças ao seu redor. No que se refere à composição das anedotas bloquianas, além da coleta na experiência do autor com a meninada, ele incentivava que seus amigos e conhecidos registrassem falas que lhe serviriam de matéria prima, o que acabou tornando a graciosa experiência da criança em tema das práticas cotidianas de leitores daquele tempo. (Cf., entre outros, DE CERTEAU, 1996)

Na maioria das vezes este tipo de colaboração de terceiros veio da partir de amigos e conhecidos do autor e quando a narrativa aparecia publicada nos anedotários, quase sempre, os nomes de quem contribuiu era citado. Um exemplo de como isso ocorreu é o caso do médico e escritor João Guimarães Rosa (19081967), que na década de 1960, também era vizinho de Bloch em Copacabana e chegou a contribuir diversas vezes com o projeto bloquiano com registros de falas de seus netos e netas. (Cf. BLOCH, 1989, s.p.). Dentre as contribuições rosianas para o trabalho bloquiano, destacamos as que estavam relacionadas à sua neta mais nova, Vera Tess, a Ooó, que teve dificuldades em começar a falar (ROSA, 2003, p.11) e por isso até chegou a ser levada pelo avô para uma consulta foniátrica com Pedro Bloch (RODRGUES, 2014, p.88).

Neste contexto de influências recíprocas podemos entender o motivo de termos encontrado nos Cadernos manuscritos de Rosa - nos quais vemos quase que exclusivamente material para composição literária (GALÍNDEZ-JORGE, 2009) - alguns registros de diversas graciosas palavras que teriam sido pronunciadas por Ooó na década de 1960, quando a menina estava em fase de aquisição da 
linguagem oral (DEL RÉ; PAULA; MENDONÇA (org),2014) ${ }^{6}$. Apresentamos abaixo breves fragmentos autógrafos de Rosa, reproduzidos de seu acervo no IEB, e insistimos em mostrá-los porque, para o historiador cultural, inscrições como essas são muito importantes, pois além de serem propriamente fontes primárias de pesquisa, também são justamente o registro de falas de criança que foram ouvidas no século XX, como sugeria o projeto de seu amigo Bloch.

Em um desses trechos Rosa tenta registrar a forma como a pequena ouvia as palavras e depois as pronunciava da forma como seu organismo em formação permitia, que as tornam bastante curiosas:

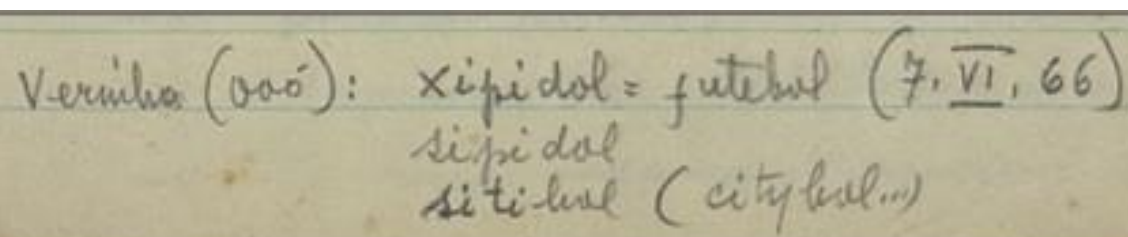

Figura 3- Fragmento com citação de Vera Tess (Ooó) falando futebol: "xipidol = futebol (7.VI.66)/ sipidol/ sitibol (citybol...)"

Fonte: (ROSA, IEB JGR-CADERNO 06, p. 46).

Semelhantes registros do vocabulário de Ooó seguem o mesmo rumo e flagram o interesse de Vovô Joãozinho na maneira pela qual a neta pequenininha ouvia as palavras e depois as reproduzia de modo peculiar. Outros registros referentes à Vera e a seu processo de entrada na linguagem oral:

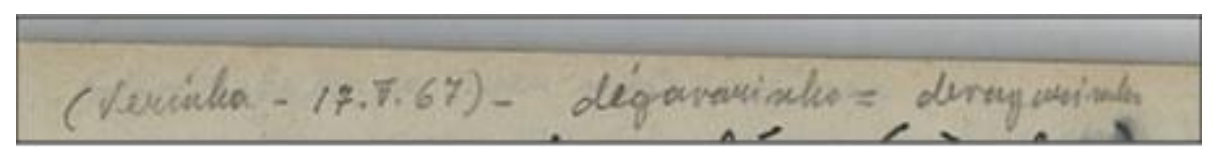

Figura 4: Fragmento com a citação de Vera Tess (Ooó), registro de Rosa sobre a neta. Nesse trecho, o registro de uma 'troca de letras' clássica entre as crianças pequenas ao começar a falar: falar 'degavarinho', querendo dizer 'devagarinho'. Fonte: (ROSA, IEB JGR-CADERNO 06, p. 55)"

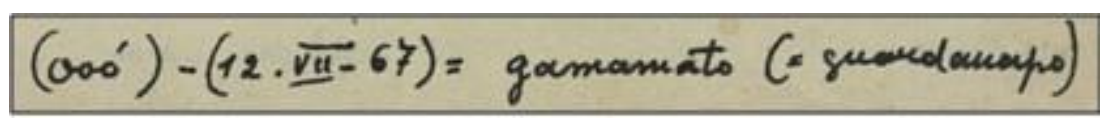

Figura 5 - Fragmento com citação de Vera Tess (Ooó). Como Verinha chamava guardanapo em 1967: gamamato! Fonte: (ROSA, IEB JGR-CADERNO 06, p. 80)

\footnotetext{
${ }^{6}$ Todas as imagens de fragmentos dos manuscritos rosianos apresentadas abaixo estão dispon ${ }^{2}$ is em (RODRIGUES, 2014, p. 157).
} 


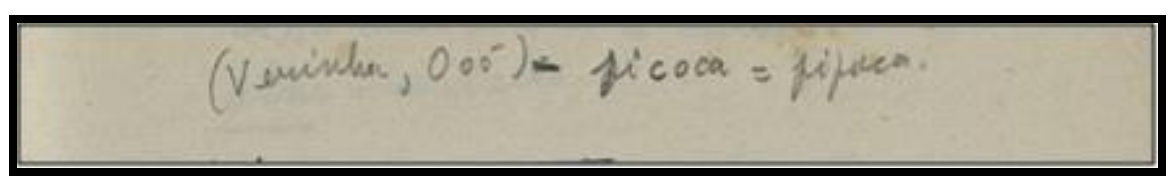

Figura 6 - Fragmentos com citação de Vera Tess (Ooó do Vovô) falando picoca: "picoca". Fonte: (ROSA, IEB JGR-CADERNO 06, p. 51)

Lembrando que outros registros das falas de Vera feitos por Rosa e que foram publicados em livro (ROSA,2003) chegaram a servir diretamente para a composição da personagem criança Menina, conto Mechéu, do livro Tutaméia (ROSA, 1967, p. 88-91), comprovando a importância do contato com uma criança tão pequena para o escritor.No caso dos registros nos Cadernos, eles ainda estão em estado mais bruto, pois foram retirados diretamente da elocução da pequena menina, então neles reparamos que como já se podia refletir sobre a criança, que até então era apenas uma fase inicial e desimportante da vida humana até que se adquirisse a maturidade adulta, destacamos que no século XX já se podia atentar, inclusive, para as formas com as quais as crianças se expressavam, porque elas poderiam abrir as portas de entrada para a apreensão infantil e contribuir para compreensão da cosmologia da meninada e perceber essa diferença pontua uma mudança que estava acontecendo na própria ideia de criança, que então passava a ser vista como interlocutora legítima no diálogo histórico-social.

Ampliando o enfoque do projeto bloquiano de destacar as locuções infantis, lembramos que essas iniciativas não estavam sozinhas na esfera do imaginário sobre crianças e infância mundialmente na época. Um caso exemplar está nas reflexões do filósofo alemão Walter Benjamin (1892-1940), que também chegou a anotar as primeiras falas de seu filho Stefan (1918), material que até chegou a ser publicado (BENJAMIN, 2011), mas que ainda não possui tradução brasileira. Sabemos também que o autor escreveu diversos textos a respeito do mundo infantil, dentre eles selecionamos um que nos parece especial, A Berlin Chronicle (BENJAMIN, 1992), pois nele Benjamin se debruça sobre suas próprias memórias perceptivas e sonoras de infância. Sobre este texto Willi Bolle, um reconhecido pesquisador benjaminiano, comenta: 
Walter Benjamin insiste particularmente na escavação das palavras primitivas que jazem soterradas sob as palavras dos adultos. Palavras tais como a criança as ouvia e entendeu pela primeira vez e nas quais se condensa, como num mineral, o universo de sua percepção. (BOLLE, 2000, p. 318)

Atentar para essas primeiras percepções infantis da nossa realidade cultural parece ser também uma porta de acesso a outro mundo, anterior a toda nossa lógica e tradição, implicando em uma desnaturalização que pode nos despertar o riso ou ao sorriso libertador (RODRIGUES, 2016a). Talvez fosse respirando este oxigênio de ideias que Bloch dava aos pais o importante conselho de incitar a comunicação verbal (DAVIS, 1979) em seus filhos, afinal:

Só se aprende a falar ouvindo, participando do meio ambiente. [...] Hoje, mais do que nunca é preciso ouvir a criança, estabelecer diálogo com ela, mesmo que ela ainda não se comunique por palavras. Quando temos a sorte de lidar com criança sem maiores problemas, então, é indesculpável que não lhe faça brotar o que tem de mais importante, mais rico, mais valioso: - a palavra, cada vez mais significativa, cada vez dizendo mais, cada vez traduzindo melhor o que vai na mente, o que vai no sentir. (BLOCH, 1980, p. 04-5)

Esta valorização da expressão oral, tão bem aceita pelas crianças de todas as idades, foi uma das tendências mais reconhecidas no século $X X$, por isso naquele século vimos surgir tantos escutadores do mundo, inclusive das crianças (Cf. RODRIGUES, 2016b).

\section{considerações finas: escutadores de criança do século $x x$}

Já mencionamos várias vezes neste texto a relação estabelecida entre o projeto bloquiano com a meninada e o esboço de uma nova definição de criança que se percebeu no Brasil especialmente a partir do final da década de 1960, quando o trabalho de Bloch começou a se efetivar, mas como seria essa nova criança, que não estava mais diretamente ligada à família ou à escola e já possuía autonomia, sendo até interlocutora e criadora, que então surgia? Nosso doutor tentou explicar:

O que é uma criança? [...] A criança é um todo, uma realidade concreta. Pode e deve crescer, em todos os aspectos, segundo suas leis evolutivas. Ela pode se moldar às técnicas e atitudes que favoreçam seu crescimento, se elas tomam em consideração suas possibilidades afetivas, sensoriais e intelectuais. [...] Sua evolução afetiva condiciona sua evolução intelectual, suas capacidades de recepção, de memorização, de integração, de expressão. A linguagem falada é a base da comunicação. Sua aquisição 
normal é indispensável ao progresso do desenvolvimento intelectual. A comunicação é própria das sociedades humanas. Normalmente constituída, ela conduz à formação de indivíduos de valor ampliado, mais equilibrados, fatores (sic) de paz e progresso. (BLOCH, 1967, p. 112)

Destaca-se nessa fala, como novidade para a época, a noção da criança como um ser único e portador de relativa autonomia, mesmo que ainda em formação, mas já não mais não como um apêndice da família ou do mundo adulto -, pois ela já podia ser vista como alguém com desejos próprios e que também é capaz de expressar sua linguagem, por isso já era possível não apenas se preocupar com ela, mas especialmente atentar para suas formas de apreensão e percepção, pois assim teríamos acesso ao mágico universo que os pequenos habitam. Perceber e considerar esse tipo de fluxo, que pode levar a cogitar a criança não apenas como receptora de estímulos culturais disponibilizados a ela pelos adultos, mas também como produtora de objetos e significados culturais, o que nos aponta uma nova maneira de se considerar a História da Infância no século $X X$, a que considera também a posição dos pequenos sobre si mesmos.

$\mathrm{Na}$ mesma linha de pensamento, em outro volume bloquiano, quando, se dirigindo aos pais e professores, Boch vai expor seu conhecimento sobre o mundo e a linguagem da meninada e chega a dar dicas importantes sobre como dialogar com os pequenos

Parta sempre do princípio de que "criança não é só isso". Ela é sempre muito mais do que o adulto imagina. Uma pequena frase pode ser dilatada.Uma descrição limitada pode, com pequenos estímulos, ser ampliada, desde que a solicitação seja bem feita. As transformações vão surgindo e se expandido. A capacidade de comunicação vai ser paralela à capacidade de socialização estimula-se o quê? A troca de ideias, a convivência, a tolerância, o desvendar do mundo, o despertar para a vida.

-Há quem imagine que a criança não usa a ironia.

-Usa!

-E como! Numa de minhas historinhas, uma menina que estava se comportando mal, pintando e bordando, é repreendida pela mãe: “Menina, você sabe o que é 'educação'? E ela, com a carinha mais inocente do planeta: "Nem desconfio!"

Muito adulto nem desconfia do quanto uma criança pode realizar, do quanto pode desenvolver, do muito que pode progredir, mediante o amor e a segurança que lhes são proporcionados [...] Costumo repetir sempre que um dos direitos fundamentais da criança é o direito a linguagem. Uma das melhores coisas que se pode fazer por um menino 
é aprender a ouvi-lo Ele tem uma fome insaciável de se pôr à prova, de se testar. (BLOCH, 1985, p. 15-6. Grifo nosso)

Enfatiza-se neste trecho a confiança na plena capacidade de expressão oral da criança, que certamente pode se desenvolver em formas mais elaboradas de linguagem como a ironia, que já é uma entrada para que a criança produza narrativas proporcionalmente destinadas ao riso e ao sorriso, que aqui chamamos de Humor. Em Diversão partilhada, humor e ironia (DEL RÉ; PAULA; MENDONÇA, 2014, p. 50) lemos sobre algumas pesquisas realizadas com crianças brasileiras e francesas, com o objetivo de "identificar as premissas do humor e da ironia na produção de enunciados" daquela meninada e percebe-se a mesma coisa que apontava Bloch na citação acima : a criança pode produzir discurso irônico para fazer adultos e crianças rirem.

A respeito de humor infantil, trabalhos como o supracitado ainda são recentes no Brasil, mesmo assim já são conhecidas pesquisas relacionadas ao humor infantil que, seguindo tendência mundial (ATTARDO, 2014, p.122), estão diretamente relacionadas ao estudo da época da aquisição de linguagem, fase onde o humor atua efetivamente como filtro facilitador na sua comunicação com o adulto (FIGUEIRA,2000). Lembrando que já contamos com equipes de pesquisa sobre comicidade e o riso das crianças que atuam em parceria com grupos internacionais ${ }^{7}$. Nesses casos, um dos temas mais abordados centra-se na reflexão sobre situações nas quais a criança e o adulto riem juntos, mas nem sempre essa gargalhada simultânea surge pelo mesmo motivo para ambos - o que seria um caso de diversão partilhada -, pois os adultos costumam rir de enunciados mais elaborados, construídos a partir de um repertório ainda desconhecido das crianças, por isso defendemos que estes possuem culturas humorísticas diferentes e a comicidade é uma das formas de tentar aproximar estes estados de percepção. (DEL RÉ; PAULA; MENDONÇA, 2014).

As narrativas humorísticas construídas por Bloch, seguindo a agilidade da

\footnotetext{
${ }^{7}$ Como exemplo destacamos o já citado trabalho da professora e pesquisadora Alessandra Del Ré (UNESP Araraquara), que além de liderar o grupo de pesquisa sobre humor infantil $\mathrm{Na}$ Lingua (CnPQ BR), também é membro do grupo COLAJE (Universidade de Paris III) e investiga especialmente a questão da diversão compartilhada e a produção de humor entre adultos e crianças(DEL RÉ; DODANE; MORGENSTERN, 2015, p. 124-25).
} 
fala, possuíam características próprias e eram quase sempre expressas em ligeiras anedotas, que são capazes de promover um choque libertador na percepção comum adulta. Como vimos alguns exemplos, refletindo sobre esse posicionamento e criando anedotas, nosso humorista contribuiu com composições complexas a partir de diálogos com crianças, nas quais diversas noções humorísticas colidem.

Por perceber e lidar com a diferença nas culturas humorísticas entre adulto e criança o foniatra Pedro Bloch criou uma noção própria de comicidade infantil e com ela não apenas registrou e valorizou a voz da criança, mas também a convocou para novos papéis, marcando uma mudança em sua definição, pois já era vista como um ente social, tanto que nas anedotas elas aparecem como coautoras e críticas, em plena produção cultural, transformando constantemente o humor em uma ferramenta para construir e compreender o fenômeno infância.

Em geral o projeto bloquiano coloca em confronto a cosmologia dos pequenos em relação às noções do adulto letrado e esse embate, que até pode vir a ser engraçado, é muito importante para o historiador cultural do humor, pois aqueles textos são contribuições de alto teor histórico - pois mostram face de uma mudança de percepção que estava acontecendo a partir da segunda metade do século $X X$ - , e também historiográfico, pois esse conteúdo condensado e gracioso da ótica infantil é legitimamente expresso nas anedotas, que possuem uma comicidade que mais do que apenas provocar o riso, desejam questionar o amenizar conflito cultural entre adulto e criança.

Tomada essa nova noção de criança que as narrativas cômicas de Pedro Bloch analisadas em nossa pesquisa nos ajuda a desenhar, é importante sublinhar que a ideia bloquiana foi sempre fazer emergir o posicionamento dos pequenos sobre o mundo, a vida e a comicidade e considerar a voz da criança como legitima, ainda que não fosse considerada nas narrativas de História escritas sobre ela. Continuamente muito interessado nas questões da voz, Pedro Bloch procurou ouvir, em alto e bom som, a até então calada voz das crianças de seu tempo, ainda que esse som viesse sempre cheio de estranhamento e comicidade. 
Como epígrafe de um de seus primeiros livros sobre foniatria, o autor narra:

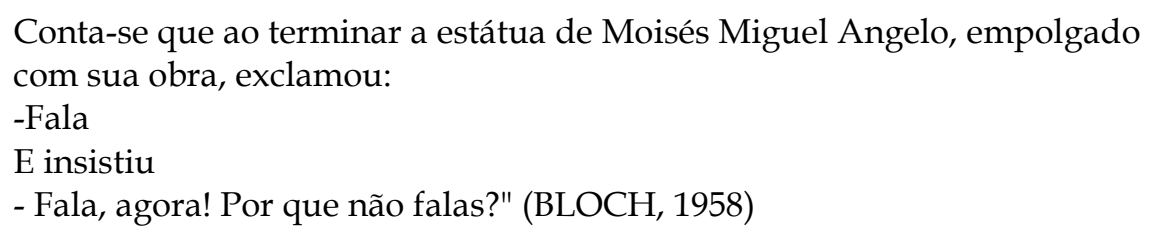

Julgamos que esta epígrafe sintetiza todo o seu projeto com os pequenos, afinal fazia parte da sua pedagogia não deixar de dizer a toda criança que encontrava "você é boa, bonita, inteligente porque sei o que uma observação assim significa para um ser que brota" (BLOCH, 1974a, p. 193), então é como se conseguisse enxergar em suas crianças - fossem pacientes, leitoras, personagens ou coautoras - algo precioso que só então estava se revelando e elas lhe chegassem lindas, inteligentes, divertidas, com uma porção de significados desconhecidos que o levava a olha-la e dizer : Fala, agora! Por que não falas? E em suas anedotas as crianças enfim falaram, contando como era o seu maravilhoso mundo encantado, no qual os adultos ainda não haviam arriscado adentrar.

\section{referências}

ATTARDO, Salvatore (org). Encyclopedia of humor studies. New York: SAGE Publications, 2014. (versão eletrônica).

BENJAMIN, Walter. A Berlin Chronicle. In: One-way Street and another writtings. Trad. Edmund Jephcott e Kingsley Shorter. London: Verso, 1992.

BENJAMIN, Walter. A hora das crianças: narrativas radiofônicas de Walter Benjamin. Trad. Aldo Martins. Rio de Janeiro: NAU, 2015.

BENJAMIN, Walter. Walter Benjamin. Archives, éd. française Florent Perrier. Trad. Philippe Ivernel. Paris: Klincksieck, 2011.

BERGSON, Henri. O Riso. Trad. Ivone. Castilho Benedetti. 2. ed. São Paulo: Martins Fontes, 2007. (Tópicos).

BLOCH, Pedro. A sabedoria da criança: você conhece seu filho? Ilust. Natto Gomes.

Rio de Janeiro: Bloch, 1998.

BLOCH, Pedro. Criança diz cada uma! Ilust. Augusto Rodrigues. Rio de Janeiro:

Biblos, 1963.

BLOCH, Pedro. Criança é isso ai. Rio de Janeiro: Bloch, 1980.

BLOCH, Pedro. Criança sabe das coisas. Rio de Janeiro: Bloch,1984.

BLOCH, Pedro. Dicionário de anedotas: de crianças para adultos. Rio de Janeiro: Revinter, 2001.

BLOCH, Pedro. Dicionário de Humor infantil. 3. ed. Ilust. Mariana Massarani. Rio de Janeiro: Ediouro, 1998a.

BLOCH, Pedro. Essas crianças de hoje. Rio de Janeiro: Bloch, 1970. 
BLOCH, Pedro. Essas crianças fabulosas. Ilust. Gilberto J. Ferreira. Rio de Janeiro: Bloch, 1987.

BLOCH, Pedro. Esses meninos de ouro!. Ilust. Jordi. Rio de Janeiro: Bloch, 1983.

BLOCH, Pedro. O incrível humor da criança. Ilust. Sidney Ferreira da Silva. Rio de Janeiro: Bloch, 1989.

BLOCH, Pedro. O menino falou e disse. Rio de Janeiro: Bloch, 1974.

BLOCH, Pedro. O problema da gagueira. Rio de Janeiro: Brasiluso, 1958a. (Coleção Fala)

BLOCH, Pedro. Outras de 'Criança diz cada uma!' Ilust. Dil, Luiz Sá e Martha Alencar.

Rio de Janeiro: Ediouro, 1983a.

BLOCH, Pedro. Pedro Bloch entrevista. Rio de Janeiro: Bloch, 1989.

BLOCH, Pedro. Poxa, que meninos! Rio de Janeiro: Bloch, 1977.

BLOCH, Pedro. Você tem personalidade? 2. ed. Rio de Janeiro: Bloch, 1974a.

BOLLE, Willi. Fisiognomia da metrópole moderna: Representação da história em Walter Benjamin. São Paulo: Edusp, 2000.

BOLOGNESI, Mario Fernando. Palhaços. São Paulo: UNESP,2003.

BREMMER, Jan; ROODENBURG (org). Humor e História. In: Uma história cultural do humor. Trad. Cynthia Azevedo; Paulo Soares. Rio de Janeiro: Record, 2000.

DE CERTEAU, Michel. A invenção do cotidiano: 1. Artes de fazer. Trad. Ephraim Ferreira Alves e. Lúcia Endlich Orth., Petrópolis: Vozes, 1996.

DEL RÉ, A; PAULA, L.; MENDONCA, M. C. (Org.). Explorando o discurso da criança. 1. ed. São Paulo: Contexto, 2014.

DEL RÉ, Alessandra; DODANE, Christelle e MORGENSTERN, Aliyah. De l'amusement partagé à la production del'humour chez l'enfant. In: FARHAT, Mokhtar; LACOSTE, Francis. (org). L'HUMOUR -Dans le bassin méditerranéen Contacts linguistiques et culturels. Tunisie: Nouha Éditions, 2015.

CHEVALIER, Jean; GHEERBRANT, Alain. Dicionário de símbolos- mitos, sonhos, costumes, gestos, formas, figuras, cores, números. Trad. Vera da Costa e Silva; Angela Melim e Lúcia Melim. 21. ed. Rio de Janeiro: José Olympio, 1994, p. 690.

COHN, Clarice. Antropologia da criança. Rio de Janeiro: Jorge Zahar, 2009.

DAVIS, Flora. A Comunicação não-verbal. Trad. Antonio Dimas. São Paulo: Summus, 1979.

DUARTE, Regina Horta. Noites circenses: espetáculos de circo e teatro em Minas Gerais no século XIX. Campinas: Unicamp, 1995.

FIGUEIRA, Rosa Attié. Dados anedóticos: quando a fala da criança provoca o riso... Humor e aquisição da linguagem. Língua e instrumentos linguísticos, Campinas, v.6, p. 27-61, 2000.

FREUD, Sigmund. El chiste y su relación con lo inconsciente. Buenos Aires: Santiago Rueda, 1953. (Obras completas, vol.3).

GALÍNDEZ-JORGE, Verônica. Fogos de artifício: Flaubert e a escritura. São Paulo: Ateliê Editorial, 2009.

HUIZINGA, Johan. Homo Ludens - O jogo como elemento da cultura. Trad. João Paulo Monteiro. 5. ed. São Paulo: Perspectiva, 2001.

PIRANDELLO, Luigi. O humorismo. In: Ginsburg, Jacob (org). Do teatro no teatro. São Paulo: Perspectiva, 1999.

POSSENTI, SÍRIO. Os humores da lingua: análises linguísticas de piadas. Campinas: Mercado das Letras, 1998. 
RODRIGUES, Camila. Escrevendo a lápis de cor: Infância e História na escritura de Guimarães Rosa. Tese (Doutorado em História Social), Universidade de São Paulo, 2014.

RODRIGUES, Camila. A hora da história das crianças (resenha). História da historiografia. Ouro Preto; Rio de Janeiro. v. 22, p. 289-294, 2016a. Disponível em: < https:/ /www.historiadahistoriografia.com.br/revista/article/view/1160/663>

RODRIGUES, Camila. Vovô Joãozinho de chupeta: Correspondência de Guimarães Rosa para Vera Ooó e novas visões sobre a criança no século XX. In: Angelus Novus, São Paulo, v. 10, p. 227-252, 2016b. Disponível em: < http:/ / www.revistas.usp.br/ran/article/view/124004 >

ROSA, João Guimarães. Caderno de Estudos para a obra 06. Arquivo do Instituto de Estudos Brasileiros USP Fundo João Guimarães Rosa / Cadernos e Cadernetas, JGR Caderno 06.

ROSA, João Guimarães. Ooó do vovô: correspondência de João de Guimarães Rosa, o vovô Joãozinho, com Vera e Beatriz Helena Tess, de setembro de 1966 a novembro de 1967. São Paulo Edusp; Imprensa Oficial; Belo Horizonte: Editora PUC/Minas, 2003.

ROSA, João Guimarães. Tutaméia: terceiras estórias. 1.ed. Rio de Janeiro:JoséOlympio, 1967. SALIBA, Elias Thomé. Raízes do riso: a representação humorística na história brasileira: da Belle Époque aos primeiros tempos do rádio. São Paulo: Cia das Letras, 2002.

recebido em: 27.09 .2017

aceito em: 16.11.2017 